\title{
Roles of sigma-1 receptors on mitochondrial functions relevant to neurodegenerative diseases
}

\author{
Tzu-Yu Weng ${ }^{1,2}$, Shang-Yi Anne Tsai ${ }^{1}$ and Tsung-Ping Su ${ }^{1 *}$
}

\begin{abstract}
The sigma-1 receptor (Sig-1R) is a chaperone that resides mainly at the mitochondrion-associated endoplasmic reticulum (ER) membrane (called the MAMs) and acts as a dynamic pluripotent modulator in living systems. At the MAM, the Sig-1R is known to play a role in regulating the $\mathrm{Ca}^{2+}$ signaling between ER and mitochondria and in maintaining the structural integrity of the MAM. The MAM serves as bridges between ER and mitochondria regulating multiple functions such as $\mathrm{Ca}^{2+}$ transfer, energy exchange, lipid synthesis and transports, and protein folding that are pivotal to cell survival and defense. Recently, emerging evidences indicate that the MAM is critical in maintaining neuronal homeostasis. Thus, given the specific localization of the Sig-1R at the MAM, we highlight and propose that the direct or indirect regulations of the Sig-1R on mitochondrial functions may relate to neurodegenerative diseases including Alzheimer's disease (AD), Parkinson's disease (PD), Huntington's disease (HD) and amyotrophic lateral sclerosis (ALS). In addition, the promising use of Sig-1R ligands to rescue mitochondrial dysfunction-induced neurodegeneration is addressed.
\end{abstract}

Keywords: Sigma-1 receptor, Mitochondria, Mitochondrion-associated ER membrane (MAM), Neurodegenerative disorders

\section{Background}

The sigma-1 receptor (Sig-1R) is an endoplasmic reticulum (ER) chaperone protein located primarily at the mitochondrion-associated ER membrane (MAM) that plays a variety of important roles in the cell. One of the functions of the Sig-1R is to regulate $\mathrm{Ca}^{2+}$ signaling between the ER and mitochondria for example by coupling to ankyrin B and inositol 1,4,5-trisphosphate receptor (IP3R) [1]. Sig-1R acts in an agonist/antagonist-sensitive manner to coordinate the coupling of ankyrin $\mathrm{B}$ to type 3 IP3R (IP3R3) to control $\mathrm{Ca}^{2+}$ signaling. The signaling pathway between Sig-1Rs, IP3R3s, and $\mathrm{Ca}^{2+}$ was found to relate to cellular survival against ER stress. When facing ER stress, the Sig-1R dissociates from cognate cochaperone BiP and acts as a free chaperone to stabilize IP3R3s to increase $\mathrm{Ca}^{2+}$ signaling from ER into mitochondria to facilitate the production of ATP [2]. The Sig-1R

\footnotetext{
* Correspondence: TSU@intra.nida.nih.gov

${ }^{1}$ Cellular Pathobiology Section, Integrative Neuroscience Branch, Intramural Research Program, National Institute on Drug Abuse, NIH, DHHS, IRP, NIDA NIH, Triad Bldg. suite 3512, 333 Cassell Drive, Baltimore, MD 21224, USA Full list of author information is available at the end of the article
}

also regulates $\mathrm{Ca}^{2+}$ influx by attenuating the coupling of the ER $\mathrm{Ca}^{2+}$ sensor STIM1 to Orai1 [3]. Crottès et al. studied the relationship between Sig-1R and ion channels in cancer cells, they reported that cancer cells expressed active Sig-1Rs that modulated a variety of ion channel families [4]. Sig-1Rs effectively altered the cell's electrical plasticity, allowing the cell to become better suited for survival in a cancerous environment. The Sig-1R has also been implicated as an ion channel regulator in amyotrophic lateral sclerosis (ALS), a neurodegenerative disease that affects motor neurons. It was recently shown that motor neurons have the highest levels of Sig-1Rs in the central nervous system (CNS), and that Sig-1Rs may help direct the flow of ions through potassium channels [5]. This would be a way of reducing the excitability of motor neurons, therefore slowing the progression of ALS.

As well related to the ALS example, the Sig-1R may involve in the development and maintenance of axons and neurons. Sig-1R-lipid interactions are important in both oligodendrocyte (OL) differentiation and axon extensions. Sig-1Rs target galactosylceramide (GalCer)and cholesterol-enriched lipid microdomains on the ER 
of OLs, and may thus modulate myelination by controlling the dynamics of the lipid transport to the myelin membrane [6]. Recently, Tsai et al. reported that the Sig$1 \mathrm{R}$ can modulate tau phosphorylation and axon development through an association with myristic acid and the cdk 5 activator p35 $[7,8]$. The Sig- $1 \mathrm{R}$ binds myristic acid to facilitate the myristoylation of p35 and promote the p35 turnover which, as a result, reduces the available p25 which would otherwise over-activate cdk5 leading to the hyperphosphorylation of Tau and retardation of axon growth. Hippocampal dendritic spine formation is also regulated by Sig-1Rs. The redox state of neurons determines the activity of the ER-mitochondrion-TIAM1Rac1 GTP signaling pathway that is a component of dendritic spine development. The Sig-1R plays a part in this process by scavenging free radicals that would otherwise cause oxidative stress at the beginning of the pathway and attenuate dendrite formation [9].

Dysregulation of axonal maintenance may cause neurodegenerative and psychiatric disorders, such as Alzheimer's disease (AD), Parkinson's disease (PD), and schizophrenia. It has been shown that functional Sig-1Rs can help mitigate symptoms of some neurodegenerative disorders, although they can also be involved in the establishment of certain other diseases [10]. For this reason, Sig-1R ligands, both agonists and antagonists, are of great interest as potential therapeutic agents against CNS disorders.

The Sig-1R has also been shown to help protect cells from mitochondria-derived reactive oxidative species (ROS) associated damages. IRE1 is one of three ER stress sensors specifically located at the MAM to respond to stress caused by mitochondria or ER-derived ROS [11]. Upon ER stress, IRE1 undergoes dimerization and phosphorylation leading to its active endonuclease form. IRE1 then splices XBP1 mRNA with the end result being an upregulation of ER chaperones that can help mitigate stress. The Sig- $1 \mathrm{R}$ mediates this process by stabilizing IRE1 during its activation.

The Sig-1R has an important function in regulating gene transcription. It was discovered that the Sig-1R, which normally localizes at the ER, can translocate to the nuclear envelope where it binds emerin that in turn recruits barrier-to-autointegration factor (BAF) and histone deacetylase (HDAC) to form a complex with specific protein $3(\mathrm{Sp} 3)$ which can then suppress the gene transcription of monoamine oxidase B (MAOB) [12].

Thus, the Sig-1R plays a role in the mediation of many cellular functions, making it a protein of great interest for treatments of neurological disorders.

\section{Sig-1R regulates mitochondrial functions}

Mitochondria are intracellular "powerhouse" organelles responsible for certain biogenesis and fundamental cellular energy processes [13]. Unlike other organelles in the cell, they are pretty much functionally autonomous since mitochondria have their own set of genomes mitochondrial DNA (mtDNA) [14], and can generate cellular energy. Most scientists prefer the endosymbiotic theories that the mitochondrial origin traces back to 1.5 billion years ago, arising from the endosymbiotic $\alpha$-proteobacteria, in which free-living proteobacteria were taken inside another cell to form an endosymbiont and later evolved into an organelle [15]. Mitochondria contain multiple membrane compartments like their ancestors, including outer membrane, intermembrane space, inner membrane, boundary membrane, cristae and matrix [16]. Mitochondrion is also a dynamic organelle with constitutive fission, fusion, and is able to migrate or undergo mitophagy for manipulating the population of mitochondria and maintaining the metabolic homeostasis in different metabolic states $[17,18]$.

Mitochondrion is noted as a main source of ATP through oxidative phosphorylation that takes place in the inner membrane, comprising a series of respiratory chain complexes work cooperatively to drive the ATP production [16]. Apart from this, other metabolic process such as citric acid cycle (TCA cycle or Krebs cycle), synthesis of the heme groups and $\beta$-oxidation of fatty acids all occur in mitochondria [19]. Mitochondria also play important role in the $\mathrm{Ca}^{2+}$ signaling [20], production of ROS [21] and cellular apoptosis [22]. Therefore, mutation of the genes in mtDNA or nuclear genes coding for the metabolic process as well as dysfunction of some direct or indirect regulations of the mitochondrial proteins can lead to mitochondrial dysfunctions, causing multiple symptoms and diseases [23, 24].

The discovery of MAM dated back in the late 1950s when the association between ER and mitochondria was first identified by the electron microscopic examination in fish gills [25]. Subsequent studies with a sequel of improved protocols led to the isolation and characterization of biochemically distinct domains of ER-interacting mitochondria [26, 27]. To date, it is generally recognized that ER and mitochondria form contact sites via proteins that tether ER and mitochondrial membranes [28, 29]. These microdomains at ER-mitochondria junctions govern diverse cellular functions such as $\mathrm{Ca}^{2+}$ transfer, energy exchange, lipid synthesis and transports, and protein folding that are pivotal to cell survival and defense. Residing at the ER-mitochondra contact sites, Sig-1Rs not only regulate $\mathrm{ER} \mathrm{Ca}^{2+}$ levels and protein degradations, they also govern cellular activities that take place within that specific MAM domain. Therefore, the Sig-1Rs serve as a communicator that bridges these two organelles and plays pivotal roles in mitochondrial functions. The Sig- $1 \mathrm{R}$ and the mitochondrion both play multiple roles in the cell. Mitochondria are the main regulator of cell survival/death as well as that for the ROS production. How Sig-1Rs exert 
their cellular activities through direct or indirect regulations of mitochondrial functions will be described and/or proposed as follows.

\section{Maintains mitochondrial integrity}

Microdomain of high $\mathrm{Ca}^{2+}$ ion concentration is transiently generated in proximity to IP3 (inositol 1,4,5-trisphosphate)-sensitive channels and is surveyed by nearby mitochondria [30-32]. This microdomain for efficient $\mathrm{Ca}^{2+}$ transfer is called mitochondrial associated ER membrane (the MAM) [33, 34]. $\mathrm{Ca}^{2+}$ ion releasing from ER into the mitochondrial matrix can affect mitochondrial functions including the activation of metabolic enzymes for ATP production and the promotion of apoptosis cascades [35]. In the resting state, Sig-1Rs form a complex with the chaperone BiP at the MAM (Fig. 1a). Upon the ER $\mathrm{Ca}^{2+}$ depletion or the Sig-1R agonist stimulation, Sig-1Rs dissociate from $\mathrm{BiP}$ to chaperone IP3R3s, leading to a prolonged $\mathrm{Ca}^{2+}$ transfer from ER into mitochondria. Sig-1Rs can also translocate from the MAM to the entire ER network under continuously low ER $\mathrm{Ca}^{2+}$ concentration such as that caused by ER stress [2]. A splice variant of Sig-1R which lacks 47 ribonucleotides encoding for exon 2 forms a complex with Sig-1R but not with IP3R in the MAM. Therefore, overexpression of this variant interferes with normal Sig$1 \mathrm{R}$ functions such as the mitochondrial IP3R-mediated $\mathrm{Ca}^{2+}$ uptake. The Sig-1R variant also suppresses mitochondrial ATP production following ER stress, thus enhancing cellular apoptosis [36]. Overexpression of another Sig-1R variant, E102Q, impairs mitochondrial ATP production and elicits neuronal cell death [37]. These findings indicate that the Sig- $1 \mathrm{R}$ regulates mitochondrial homeostasis, and some of the Sig-1Rinteracting proteins may reside in the mitochondria. Using immunoprecipitation assay, Sig-1R was found to interact with mitochondrial Rac1 which is a critical regulator for neurogenesis, and formed complexes with IP3R and $\mathrm{Bcl}-2$ in isolated mitochondria [38]. The Sig$1 \mathrm{R}$ agonist (+)-pentazocine further increased this interaction while the antagonist haloperidol cannot. (+)-Pentazocine also led to the phosphorylation of Bad and the NADPH-dependent production of ROS, suggesting that Sig-1R might act through the Rac1 signaling to induce mild oxidative stress and cell survival pathways. The roles of Sig-1Rs on restoring $\mathrm{Ca}^{2+}$ transferring into mitochondria, ATP productions, and mitochondrial morphology have also been demonstrated in the Sig-1R agonist SA4503-treated cardiomyocytes [39]. Consequently, Sig1 Rs play an important role in maintaining mitochondrial integrity as the aberrant neuronal mitochondrial aggregates or fragments have been associated with Sig-1R deficiency. Silencing of Sig-1Rs in hippocampal neurons leads to shorter and smaller mitochondria as well as aberrant mitochondria membrane potentials [9].

\section{Improves cell survival and stress response via mitochondria}

Mitochondrial metabolism is closely related to several of the critical cellular functions including survival or

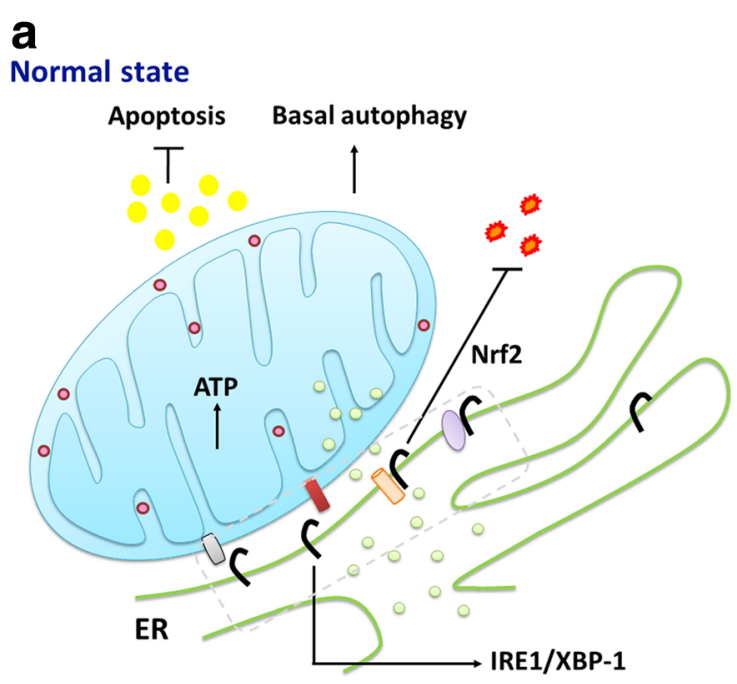

\section{b}

\section{Sig-1R deficiency}

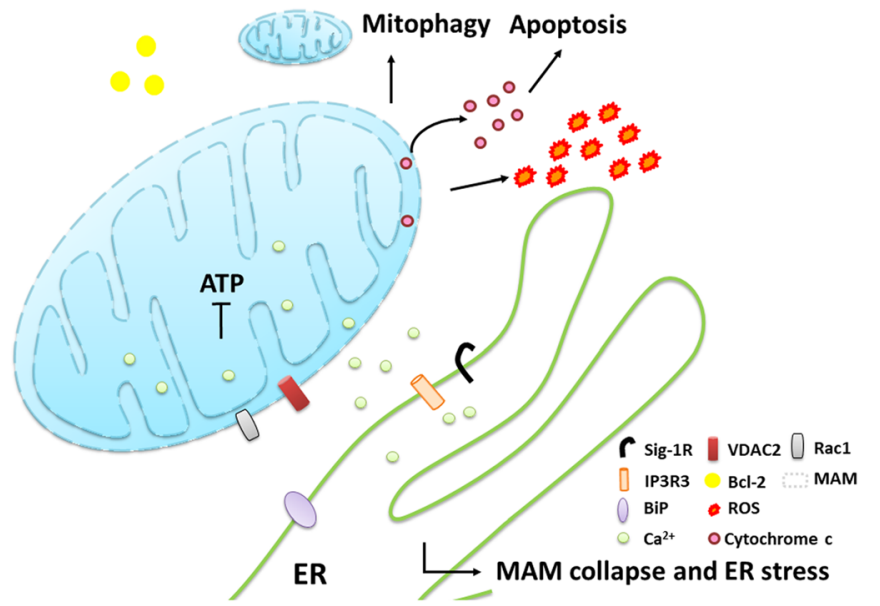

Fig. 1 The putative model of Sig-1R at the MAM. a In the normal state, the Sig-1R interacts with BiP. Upon agonist stimulation or the decline of ER $\mathrm{Ca}^{2+}$, the Sig-1R dissociates from BiP to stabilize the IP3R3 for $\mathrm{Ca}^{2+}$ signaling from ER into mitochondria and to regulate the IRE1-dependent pathway to counteract the ER stress. The Sig-1R protects against apoptosis and ROS via the Bcl-2- or Nrf2-dependent pathways. Sig-1Rs can also associate with VDAC2 or Rac1. $\mathbf{b}$ The depletion of Sig-1R leads to an abnormal $\mathrm{Ca}^{2+}$ signaling between ER and mitochondria and the disruption of the ATP production. Enhanced ROS production, increased cytochrome $c$ release, or reduced $\mathrm{Bcl}-2$ can cause ER stress that leads to the collapse of the MAM and consequently enhanced autophagy or apoptotic cell death 
apoptosis. The mitochondrial $\mathrm{Ca}^{2+}$ surge from the ER causes a mitochondrial $\mathrm{Ca}^{2+}$ overload, thus stimulating mitochondria to release multiple apoptotic factors such as cytochrome $\mathrm{c}$ that in turn activates caspase and leads to apoptosis [35]. The anti-apoptotic Bcl-2 family plays crucial roles in determining cellular survivals against apoptotic pathway [40]. It was found that the Sig-1R promoted cellular survival by regulating the Bcl-2 which at least in part exists on mitochondria, while silencing of Sig-1Rs down-regulated Bcl-2 mRNA expression and the effects were rescued by ROS scavengers or the inhibitor of the ROS-inducible transcription factor nuclear factor $\kappa B(N F-\kappa B)$. Silencing of Sig-1Rs also enhanced hydrogen peroxide $\left(\mathrm{H}_{2} \mathrm{O}_{2}\right)$-induced cell apoptosis [41]. Sig-1R agonists protected neurons against the insults caused by oxygen-glucose deprivation or glutamate stimulation through the Bcl-2 pathway [42]. The transcriptome analysis revealed that Bcl-2 levels decreased in the Sig-1R $\mathrm{KO}$ retina [43]. In addition to the Bcl-2 family, Sig-1Rs protected retinal ganglion cell against glutamate-induced cell apoptosis by regulating $\mathrm{Ca}^{2+}$ signaling and inhibiting the activation of pro-apoptotic factors such as Bax and caspase-3 [44]. Conversely, knocking down Sig-1Rs in neurons caused a decrease of mitochondrial membrane potential and the release of cytochrome c, leading to disrupted cytoskeleton networks and the consequential immature formation of dendritic spines [9]. The Sig- $1 \mathrm{R}$ is also involved in the pro-apoptotic pathways. Sig-1R ligands haven been shown to induce tumor cell death through the activation of caspase cascades, $\mathrm{Ca}^{2}$ ${ }^{+}$-dependent activation of phospholipase C (PLC), $\mathrm{Ca}^{2}$ ${ }^{+}$-independent inhibition of PI3K signaling [45], or the HIF-1 $\alpha$ pathway [46]. Methamphetamine induced microglia apoptosis by activation of the MAPK, PI3K/Akt and p53 pathways, while blockage of the Sig-1R suppressed pro-apoptotic factors such as Bax, caspase- 3 and caspase9 induced by methamphetamine [47].

ER stress stimulates cells to activate the unfolded protein response (UPR) to cope with the stress resulting from accumulation of unfolded proteins in the ER [48]. Early phases of ER stress trigger an increase in mitochondrial ATP levels and oxygen consumption which depend critically on the ER-mitochondrion coupling and $\mathrm{Ca}^{2+}$ transfer from ER into mitochondria $[49,50]$, implying the metabolic regulation of mitochondria by the ER. The three major sensors of the UPR are PERK, IRE1 and ATF6 [48]. Sig-1Rs stabilized IRE1 at the MAM when cells were under ER stress. Deficiency of Sig-1R caused cell apoptosis by compromising the IRE1-XBP1 signaling. Treatment of cells with mitochondrial ROS inducer, antimycin A, showed that the mitochondrial-derived ROS triggered the IRE1-XBP1 signaling but not the ATF6 or PERK signaling pathway toward Sig-1Rs [11]. It was suggested that the mRNA of ATF6 showed profound changes in the retinal Müller glial cells isolated from Sig-1R KO mice [43], and microarray analyses revealed that silencing of Sig-1Rs influenced the expression of genes related to the ER pathway in primary hippocampal neurons [51]. Ligand such as (+)-pentazocine could attenuate the mRNA level of ER stress proteins PERK, ATF4, ATF6, IRE1, and CHOP that were upregulated in retinal ganglion cells exposed to oxidative stress [52]. ATF4 also interacted with the $5^{\prime}$ flanking region of SIGMAR1, and transcriptionally regulated the Sig-1R in the PERK/eIF2 $\alpha / A T F 4$ pathway under ER stress [53], moreover, fluvoxamine, a selective serotonin reuptake inhibitor with affinity for Sig-1R, induced Sig$1 \mathrm{R}$ expression involving ATF4 without invoking the PERK pathway [54].

\section{Regulates oxidative stress derived from mitochondria}

Free radicals play pivotal biological roles in cells including signal transduction, gene transcription and enzymatic activity regulation. However, unbalanced ROS productions in neuronal microenvironments caused free radical-induced lipid and protein modifications and DNA damages, generated many byproducts that are harmful to the cells, and led to manifestation of neurodegenerative diseases [55]. The mitochondrion is one of the main sources that produces oxidants in cells via consumption of $\mathrm{O}_{2}$ in the aerobic respiration [55]. One might wonder how the Sig- $1 \mathrm{R}$ counterbalances the excess ROS. The Sig-1R has been reported to regulate oxidative stress responses and involve thus in the regulation of neuroplasticity through Rac1 GTPase. Paradoxically however, treatment of bovine brain mitochondria with Sig-1R agonist (+)-pentazocine led to the NADPHdependent production of ROS [38]. Activation of Sig1 Rs through agonists has been reported to mitigate cellular stress. For example, the Sig-1R agonist blocked lipid peroxidation in $\beta$-amyloid (A $\beta$ ) peptide-injected mice [56], reduced nitrosative and oxidative stress on proteins after traumatic brain injury (TBI) [57], and mitigated the oxidative stress-induced cell death in human lens cell line [58]. These observations implicate the involvement of Sig-1Rs in neuroprotection. Emerging evidence provides insights to the underlying mechanisms of oxidative insults mediated by Sig-1Rs. A report showed that higher levels of ROS were observed in the livers, lungs and hepatocytes of Sig-1R KO mice when compared to that from the WT mice, suggesting that the KO mice were under oxidative stress. Antioxidant protein peroxiredoxin $6(\operatorname{Prdx} 6)$ and the ER chaperone BiP were also increased in Sig-1R KO animals. Further analysis revealed that Sig-1R may upregulate NADPH quinone oxidoreductase 1 (NQO1) and SOD1 mRNA expression through antioxidant response element (ARE) [59]. The transcription factor Nrf2 (nuclear factor erythroid 2- 
related factor 2) binds to the ARE and regulates genes that are involved in cellular protection against oxidative stress-induced cell death [60]. Silencing of Sig-1Rs in primary hippocampal neurons also induced expression of genes related to the Nrf2-mediated oxidative stress pathway as shown from a microarray analysis [51]. Additionally, in a cellular model using Sig-1R KO Müller glia cells, the ROS levels were increased in $\mathrm{KO}$ cells with a concomitant reduced level of $\mathrm{Nrf} 2$ and the resultant Nrf2-ARE binding affinity [61]. Several genes involved in the mitochondrial metabolic process are transcriptionally regulated by Nrf2; therefore, Nrf2 also affects mitochondrial functions such as mitochondrial membrane potential, ATP synthesis, and mitochondrial fatty acid oxidation [62]. Although Nrf2 is considered as a transcription factor, it has been proposed that Nrf2 protects mitochondria from oxidant stress possibly through direct interaction with the mitochondrial outer membrane [63]. Moreover, a zinc finger protein 179 that has been identified as a Sig-1R downstream effector, exhibiting a neuroprotective role in the $\mathrm{H}_{2} \mathrm{O}_{2}$-induced $\mathrm{ROS}$ insult model [64]. The exact interactive connections between Sig-1R, Nrf2 and mitochondria as well as other neuroprotective mechanisms of Sig-1Rs in combating ROS remain to be totally clarified.

\section{Regulates autophagy via mitochondria}

Autophagy is triggered upon cells are under stress such as nutrient starvation, ER stress, and pathogen infection. It is the process that cells strive for survival by invoking self-degradation of cellular components in which double-membrane autophagosomes engulf protein aggregates, organelles, portions of cytoplasm and fuse with lysosomes for energy demand [65]. Oxidative stress damages mitochondria while mitochondrion itself is also a substrate of autophagy, namely, mitophagy [66]. There are molecules that may provide link of autophagy to the MAM including IP3R which its signaling is required to maintain the autophagy suppression. Lack of IP3R decreased mitochondrial $\mathrm{Ca}^{2+}$ uptake and activated autophagy in the AMPK pathway [35, 67]. Part of the mitophagy is initiated when PINK1 recruits Parkin that targets mitochondria, causing the ubiquitination of the mitochondrial outer membrane protein voltage-dependent anion channel 1 (VDAC1) that is further recognized by p62 for degradation $[66,68]$. Moreover, it is also suggested that autophagy originates from the MAM where nucleation of the isolation membrane may occur [69]. Therefore, emerging evidences suggest the role of the Sig-1R in autophagy. The Sig-1R antagonist 1-(4-iodophenyl)-3-(2-adamantyl)guanidine (IPAG) or haloperidol stimulated UPR and autophagic flux that depended on Sig-1R in a time-lapsed manner. UPR induction preceded autophagosome formation, and inhibition of UPR or autophagy accelerated cellular apoptosis that induced by antagonizing Sig-1R activities [70]. Silencing or loss of Sig-1Rs led to widened ER morphology, dissolution of mitochondrial cristae structure, and enhanced mitophagy in cells that were accompanied with impaired fusion between autophagosome and lysosomes, lipid raft destabilization, and impaired endolysosomal pathways [71]. Leptomycin B and thapsigargin caused the sequestration of Sig-1R within the nucleus with a resultant partial co-localization with p62 which is an important mediator in the proteasome and autophagy degradation systems [72]. Silencing of Sig-1Rs or employing the Sig-1R antagonist also demonstrated that cocaine, a Sig-1R agonist, induced autophagy in astrocytes through the Sig-1R mediated pathway [73]. Moreover, treatment of the Sig-1R antagonist increased the expression of the monosialotetrahexosylganglioside (GM1) and the accumulation of GM1 in the autophagosomes, demonstrating a relation between Sig-1R and gangliosides [74]. Interestingly, silencing of Sig-1Rs blocked autophagy at the isolation membrane expansion/LC3 lipidation stage [75], implicating the association of Sig-1R with the formation of autophpagy at the MAM as well as its ability to regulate cholesterol/lipid.

\section{Regulates lipid transport and steroidogenesis via mitochondria}

It has been demonstrated that certain lipids are imported into mitochondria, for instance, phosphatidylserines are imported into mitochondria from the MAM contact sites to decarboxylate to phosphatidylethanolamine [29]. Sig1 Rs participate in the lipid synthesis and can bind simple sphingolipids such as ceramides [76]. MAM are enriched in cholesterol and sphingolipids, and form MAM-derived detergent-resistant membranes. Those detergent-resistant microdomains also regulate the anchoring of Sig- $1 \mathrm{R}$ to the MAM. Sig-1Rs can interact with steroidogenic acute regulatory protein (StAR) and the voltage-dependent anion channel 2 (VDAC2) [77] which is a member of the mitochondrial porin family that transports metabolites across the mitochondrial outer membrane [78, 79]. At the MAM, VDAC2 regulates and interacts with StAR as a critical step to transport cholesterol into mitochondria for steroidogenesis [80]. Noteworthy, another study indicated that silencing of Sig-1Rs did not change the expression of ER and mitochondrial resident proteins but led to the reduced synthesis of pregnenolone. The interaction of the Sig-1R between VDAC2 and StAR, suggesting a role of Sig-1Rs in cholesterol trafficking and steroidogenesis at the MAM $[77,79]$. Recently, it was also demonstrated that the Sig-1R can directly interact with myristic acid, promote p35 turnover, and regulate Tau phosphorylation and axon extension $[7,8]$. The exact relation between Sig-1Rs and other lipids at the MAM remains to be clarified. 


\section{Putative Sig-1R interacting proteins in mitochondria}

Bioinformatics analyses identified several putative Sig-1R interacting proteins in mitochondria [81], including cytochrome $\mathrm{C} 1$ (CYC1), prohibitin (PHB), solute carrier family 25 member 11 (SLC25A11) and solute carrier family 25 member 39 (SLC25A39) [82]. Some of these proteins were demonstrated to be involved in the neurodegenerative disease or cellular protection. CYC1 is a subunit of mitochondrial complex III, playing roles in response to oxidative stress and the generation of superoxide anion in the mitochondrial respiratory chain [83, 84]. CYC1 is also identified as neuroglobin binding protein and the CYC1-neuroglobin association may be involved in the ATP production [83, 84]. Mitochondrial PHB families control cell proliferation, cristae morphogenesis and can regulate the fusion machinery of mitochondria [85]. SLC25 belongs to a family of transporters that functions in the shuttling of the metabolites across the inner mitochondrial membrane [86]. Inhibition of the SLC25A11 function decreased the mitochondrial GSH level in cerebellar astrocytes [87]. However, the direct demonstration of those proteins' interactions with Sig-1Rs need to be investigated; so do the functional consequences of those interactions.

\section{Mitochondrial-associated neurological disorders and Sig-1R}

Neurons and muscle cells contain high levels of mitochondria due to a high demand of energy. The CNS has a high rate of metabolism because neurons participate in facilitating the neurotransmission and extending axons and dendrites to neighboring cells for impulse transmission. Neurons exert plasticity, exhibiting complex morphologies, and constitutively undergo synaptic modulations when stimulated. Therefore, mitochondrial dysfunction can be detrimental to neurons [88] and has been extensively discussed in neurodegeneration [23, 89, 90]. Disruptions of the microdomains at ER-mitochondria contacts were found to relate to many neurological disorders [9193]. Mechanisms involved in the progression of these diseases include dysfunction of mitochondria, imbalance of the $\mathrm{Ca}^{2+}$ homeostasis, ER stress, oxidative stress and autophagy. Stationed at the MAM, the Sig-1R acts as an intracellular organelle modulator between ER, mitochondria, nucleus, and the plasma membrane upon stimulations [82]. The Sig-1R is associated with many neurological disorders [94, 95], including AD [96], PD [97], ALS [5], HD [98], stroke/ischemia [99, 100], neuropathic pain [101], and certain psychiatric disorders [102]. Emerging evidences suggest that Sig-1R functions as an amplifier of intracellular signaling [95]. Sig-1R KO impaired neurogenesis in mice with depressive-like immobility phenotype [103-105]. Deficiency of Sig-1Rs aggravates the progression in many neurodegenerative models, while reinstating Sig-1Rs or agonistic activation restores neuronal functions and alleviates disease progression. How Sig-1Rs may regulate neurodegenerative diseases via a direct or indirect regulation on mitochondria, especially via the MAM, is described in the following sections.

\section{Sig-1R in AD}

The major symptoms of $\mathrm{AD}$ include selective cognitive decline and memory loss, which are now accepted as being caused by the $A \beta$ plaques and the tau neurofibrillary tangles. $A \beta$ is generated from the serial enzymatic digestion of amyloid precursor protein (APP) which has been found to accumulate in the mitochondrial import channel in AD brains [106]. A $\beta$ also accumulates in the mitochondria of AD patients and APP transgenic mouse [107], and is associated with elevated $\mathrm{H}_{2} \mathrm{O}_{2}$ and decreased cytochrome $\mathrm{c}$ oxidase activities in an animal model [108]. A $\beta$ affects mitochondrial response to metabolic status by interacting with mitochondrial enzyme or disrupts synaptic functions by attenuating mitochondrial trafficking $[109,110]$. Recently, it has been demonstrated that $A \beta$ is generated intracellularly at MAM and may influence ER, mitochondrial and the MAM's function [111]. Afobazole, a Sig-1R agonist, could lessen the increased $\mathrm{Ca}^{2+}$ caused by $A \beta_{25-35}$ through the activation of Sig-1R. Afobazole reduced NO production, prevented upregulation of the proapoptotic protein Bax, activated caspase- 3 , and inhibited the downregulation of $\mathrm{Bcl}-2$ induced by $A \beta_{25-35}$ [112]. Up-regulation of Sig-1R was found in the APP $\mathrm{Awe}_{\mathrm{S} \text { Lon }}$ mouse brain prior to the plaque formations, while decreased Sig-1R protein levels were observed in the human cortical postmortem brain tissue [113]. The Sig-1R expression is critical to the coupling of the ER-mitochondria contacts since the activation of Sig-1R in A $\beta$-treated cells significantly increased the $\mathrm{Ca}^{2}$ + shuttling from ER into mitochondria. $A \beta$ also increased the expression of MAM-associated proteins such as IP3R3 and increased ER-mitochondria contacts in hippocampal neurons. Similar results were found in PET scan studies, in which Sig-1R expressions were lower in the brain of early AD patients [114]. On the other hand, the mitochondrial cholesterol influx was increased with concomitantly increased levels of Sig-1R and VDAC at MAMs in an old AD mouse model, indicating a relation of those MAM proteins in cholesterol trafficking [115]. Protein phosphatase 2A (PP2A) interacts with IP3R3 and Akt, and can regulate IP3R3 phosphorylation state [116]. In a brain endothelial cell culture model, okadaic acid-induced PP2A inhibition was accompanied by elevations of phosphorylated tau, ER stress markers, and Sig-1Rs as well as the $\mathrm{Ca}^{2+}$ overload in the mitochondria [117]. Brain vessels from 3xTgAD mice also showed decreased PP2A. Apolipoprotein E (APOE) is another risk factor that is implicated in AD. 
The polymorphism analysis revealed that SIGMAR1 and $A P O E$ may interact to influence the severity of $\mathrm{AD}$ [118]. Further, it was demonstrated that the ER-mitochondrion communication and the function of the MAM are increased significantly in cells treated with astrocyte conditioned medium containing APOE4 [119], suggesting a link to the Sig-1R. $\gamma$-Secretase complex is one of the enzymes that engages in the processing of APP to produce A $\beta$. The subunits of the $\gamma$-secretase complex, presenilin-1 (PS1) and presenilin-2 (PS2), have been found to localize at the MAM [120]. Increased MAM activity was detected in mouse embryonic fibroblasts lacking PS1 and PS2 [121]. Overexpression or down-regulation of PS2 caused the fluctuation of $\mathrm{Ca}^{2+}$ concentrations between ER and mitochondria [122]. In the tissues of an AD-associated mutant, PS1-E280A, the ER-mitochondrion tethering was impaired and voltagegated P/Q-type $\mathrm{Ca}^{2+}$ channels, IP3Rs and $\mathrm{Ca}^{2+}$-dependent mitochondrial transport proteins were reduced as well. Overexpression of this mutant altered the ERmitochondrion tethering and associated transport in the neuronal cell [123]. Tau proteins may be involved in the pathogenesis of $\mathrm{AD}$ through their detrimental effect on mitochondria [124, 125]. However, the association of tau and Sig-1R as well as the PS processing mechanism mediated by Sig-1R have yet to be established.

\section{Sig-1R in PD}

Parkinson's disease is a slowly progressing disorder, causing impaired motor functions such as bradykinesia or tremor, and other non-motor complications. The pathological characteristic of PD is the deposit of Lewy bodies composed of $\alpha$-synuclein, ubiquitin and neurofilaments [126]. $\alpha$-Synuclein [127, 128], Parkin, PINK1 [68, 129131], DJ-1 [132-134] and LRRK2 [135] have been demonstrated to be closely linked to the mitochondrial-related PD pathogenesis.

Sig-1R expressions were lower in putamen of PD patients as demonstrated by PET studies [114]. Dopamine toxicity is involved in the etiology of PD. Dopamine activated NF- $k B$ while Sig-1Rs counteracted and inhibited the proteasomal conversion/activation of NF-kB. Silencing of Sig-1Rs in combination with dopamine treatment caused a synergistic proteasomal conversion of NF- $\mathrm{kB}$ p105 to the active form of p50, which is known to down-regulate $\mathrm{Bcl}-2$ at the transcriptional level. Dopamine caused apoptosis in Sig-1R knockdown cells and the effects could be reversed by overexpression of $\mathrm{Bcl}-2$ [136]. Accumulation of $\alpha$-synuclein impaired mitochondrial complex I activity, and caused the release of cytochrome $\mathrm{c}$ and the elevation of mitochondrial $\mathrm{Ca}^{2+}$, nitric oxide (NO) and ROS concentrations [127, 128]. Moreover, $\alpha$-synuclein controls mitochondrial $\mathrm{Ca}^{2+}$ homeostasis by enhancing the ER-mitochondria associations [137] and was later found to exist at the MAM where it modulates the mitochondrial morphology [138]. Intriguingly, Pailluson et al. demonstrated a closer link between MAM and PD [139]. Vesicle-associated membrane protein-associated protein B (VAPB) is an ER-resident protein and protein tyrosine phosphatase interacting protein 51 (PTPIP51) is an outer mitochondrial membrane protein. Both proteins function as a bridge tethering the ER and mitochondria. Residing at the MAM, $\alpha$ synuclein also interacts with VAPB but not PTPIP51. Silencing of $\alpha$-synuclein does not alter ER-mitochondria associations, while overexpression of wild-type and familial PD mutant $\alpha$-synuclein disrupts the tethering between VAPB and PTPIP51 to loosen the ERmitochondria contacts. The actions of $\alpha$-synuclein include the loss of MAM domain, disruption of $\mathrm{Ca}^{2+}$ transferring between the two organelles, and the inhibition of ATP production. Neither expression of WT/mutant nor silencing of $\alpha$-synuclein changed the protein expression of Sig-1R, indicating that $\alpha$-synuclein may not influence the translational level of Sig-1R [139]. However, it remains to be investigated if the $\alpha$ synuclein-induced reduction of the ER-mitochondria associations may involve the Sig-1R. Parkin and PINK1 work cooperatively to regulate the homeostasis of mitochondria, such as mitochondrial fission/fusion machinery, the integrity of mitochondria or mitophagy [68, 129-131]. DJ-1 exerts its neuroprotection by regulating the function of mitochondria [134], and its mutation also caused a reduction in the level of ATP [140]. Parkin and DJ-1 can both alter the ER-mitochondria crosstalks and tethering [141, 142]. A close examination on the association between Sig-1R and those proteins may provide more insights in the future.

\section{Sig-1R in HD}

$\mathrm{HD}$ is an inherited disorder in an autosomal dominant pattern due to an elongated CAG repeat in the Huntingtin (Htt) gene, HTT, and is clinically characterized by progressive retardation in motor, cognition and psychiatric states [143]. HD mutation is associated with mitochondrial dysfunction and apoptotic pathways. Inhibition of mitochondrial function via the complex II inhibitor 3-nitropropionic acid (3NP) recapitulates HD-like symptoms in animals [144]. Mitochondrial fractionation revealed that $\mathrm{Htt}$ is present in the mitochondrial outer membrane. Mutant Htt protein induced mitochondrial permeability transition (MPT) accompanied by a significant release of cytochrome c [145]. Overexpressing of Htt proteins with 74 or 138 polyglutamine repeats induced mitochondrial fragmentation under oxidative stress, in which Htt 74 also caused cell death, reduction in ATP levels, and interference on the dynamics of mitochondrial fusion/fission [146]. Further, Htt could interact with Drp1 
which controls mitochondrial fission, elevates Drp1 enzyme activities, and induces abnormal dynamics and anterograde movements of mitochondria, thus leading to disruption of synaptic functions [147].

Expression of $\mathrm{N}$-terminal $\mathrm{Htt}$ proteins with expanded polyglutamine activates ER stress, increases BiP protein expression, and causes cell death in neuronal cells. Compound that inhibits ER stress such as salubrinal could rescue the cell death and eliminate protein aggregations resulting from mutant $\mathrm{Htt}$ proteins [148]. A similar approach was also used to investigate the relation between Sig-1R and mutant Htt. Sig-1R expression is decreased in mutant Htt protein-expressing cells [98]. Treatment of the Sig-1R agonist PRE084 counteracted the effects caused by mutant $\mathrm{Htt}$ by increasing cellular antioxidants, reducing the ROS level, increasing NF- $\kappa \mathrm{B}-\mathrm{p} 65$, and activating $\mathrm{NF}-\kappa \mathrm{B}$ signaling without changing mitochondrial $\mathrm{Ca}^{2+}$ concentration. A partial co-localization of Sig-1R with aggregates of cytoplasmic mutant Htt was observed, indicating that the Sig-1R may play some unknown roles in the $\mathrm{Htt}$ aggregates such as being hijacked by the aggregates with a loss of its function. Similar results were observed in that Sig-1Rs translocated and colocalized with the mutant $\mathrm{Htt}$ in the nucleus [149]. Although mitochondrial $\mathrm{Ca}^{2+}$ levels were not affected by mutant $\mathrm{Htt}$ proteins in this model, another report indicated that the interaction of type I IP3R with BiP was reduced in the HD mouse model that was accompany by impaired $\mathrm{Ca}^{2+}$ releasing activity of type I IP3R [150]. Moreover, a Sig-1R ligand, pridopidine was found to improve motor function in a HD R6/2 mouse model. Pridopidine increased the expression of neuroprotective factors, such as BDNF and DARPP32, and reduced the size of $\mathrm{Htt}$ aggregates in HD mice. The effect of pridopidine was abolished in the presence of Sig$1 \mathrm{R}$ antagonist in cellular model, implying that the Sig-1R was involved in the neuroprotective functions of pridopidine [151]. Pridopidine activated neuronal plasticity and survival pathways, and the Sig-1R may represent a major regulator to increase the secretion of BDNF [152]. Further, in a YAC128 transgenic HD mouse model, it was demonstrated that pridopidine prevented the loss of medium spiny neurons through Sig-1R in aging YAC128 cocultures. Pridopidine treatment also normalized the ER $\mathrm{Ca}^{2+}$ levels in medium spiny neurons in the co-culture system [153]. Although the MAM region has not been directly demonstrated to be involved in HD, the insightful information mentioned in this section implies a relation between Sig-1R's function at MAM and HD may exist.

\section{Sig-1R in ALS}

The clinical hallmark of ALS is the presence of upper and lower motor neuron dysfunction as seen in the limbs that can further manifested as muscular atrophy in other regions [154]. Mitochondrial pathology occurs as an initial event in a mouse model of ALS [155]. The motor nerve terminals from ALS patients contained abnormal $\mathrm{Ca}^{2+}$ concentrations and increased mitochondrial volumes [156]. Several risk factors have been identified in ALS and demonstrated to be involved in mitochondrial homeostasis, including SOD1 [157-159], FUS/TLS [160], TDP-43 [161], OPTN [162] and C9Orf72 [163]. SOD1 scavenges free superoxide radicals in the cells, and mutant SOD1 protein has been shown to bind to the cytoplasmic face of mitochondria [158]. SOD1 mutant mouse model demonstrated mitochondrial abnormalities, motor neuron death, and symptoms and pathology similar to those observed in ALS [157]. Motor neurons expressing mutant SOD1 also showed impairments in mitochondrial fusion in axons and soma, dysregulsation of mitochondrial retrograde axonal transport, and a reduction in the size of mitochondria [159].

Sig-1R proteins were reduced in the lumbar spinal cord of ALS. They were also accumulated in enlarged Cterminals and ER structures of alpha motor neurons. The disrupted Sig-1R localization was also observed in SOD1 transgenic mice [164]. A Sig-1R KO mouse model showed muscle weakness and motor neuron loss, and the inhibition of mitochondrial fission caused defect in mitochondrial axonal transport and axonal degeneration that were similar to that seen in Sig-1R deficiency samples. Those defects can be restored by the $\mathrm{Ca}^{2+}$ scavenging and ER stress inhibition in motor neurons [165]. The collapse of the MAM (Fig. 1b) was demonstrated as a common mechanism in Sig-1R- and SOD1-linked ALS models [166]. Watanabe et al. found that a homozygous mutation p.L95fs of SIGMAR1 was identified in the inherited juvenile ALS. The mutant variant of Sig-1R showed reduced stability and was incapable of binding to IP3R3s. The mutant SOD1 was also detected at the MAM where the mutant was observed in neurons but not in astrocytes or other cell types of the SOD1 mouse model. Furthermore, deficiency of Sig-1Rs accelerated the onset of SOD-1-mediated ALS in mouse model. Deficiency of Sig-1R or accumulation of mutant SOD1 could induce the collapse of the MAM, leading to the mislocalization of IP3R3s, the activation of calpain, and the dysfunction of mitochondria. Administration of the Sig-1R agonist PRE-084 restored the Sig-1R-IP3R3 interaction and prevented the Sig-1R aggregation [166]. TDP-43 was found to form hyper-phosphorylated, ubiquitin-positive inclusions in ALS [167], and the ALS disease-associated mutant TDP-43 exhibited greater extent of mis-localization in mitochondria [161]. Moreover, pathologic TDP-43 that perturbs the ER-mitochondrion association was also observed [168]. The association of Sig-1R and TDP-43 was documented in a study in which a nonpolymorphic mutation in the 3 '-untranslated region of SIGMAR1 was identified in patients from the 
frontotemporal lobar degeneration-motor neuron disease (FTLD-MND) pedigree [169]. Brains of SIGMAR1 mutation carriers showed cytoplasmic inclusions of TDP-43 or FUS. Overexpression of Sig-1R increased the mislocalization of TDP-43 and FUS from the nucleus to the cytoplasm while Sig-1R antagonists reduced the cytoplasmic to nuclear TDP-43 ratio. The mutation of the SIGMAR1 (p.E102Q) has also been found in the ALS patients [170]. Overexpression of this mutant increased mitochondrial damage, induced autophagic cell death, and led to mislocalized TDP-43 [37, 171]. The Sig-1R was observed in the neuronal nuclear inclusions in various neurodegenerative diseases, suggesting that the Sig$1 \mathrm{R}$ might move laterally between the nucleus and the cytoplasm under certain conditions [72]. Those findings suggest a role of Sig-1R as well as the importance of MAM integrity in ALS.

\section{Sig-1R endogenous ligands in neurodegenerative diseases}

In addition to the synthetic agonists and antagonists listed above, the endogenous ligands of Sig-1Rs include the steroids (progesterone, DHEA-sulfate and testosterone) [172, 173], hallucinogen N,N-dimethyltryptamine (DMT) [174], sphingosine $[175,176]$ and monoglycosylated-ceramide $[76,177]$. Progesterone was found to regulate free radical metabolism in brain mitochondria and provides neuroprotective and anti-inflammatory effects in the CNS [178, 179]. A motor neuron degeneration mouse model showed less pronounced abnormal mitochondria morphologies after receiving progesterone [180], and progesterone also regulate AD-like neuropathologies in female 3xTg-AD mice [181]. Some steroids and progesterone are synthesized at specific location of ER, and progesterone can inhibit the dissociation of Sig-1R and BiP [2, 182]. On the contrary, pregnenolone sulfate also caused the dissociation of an ankyrin B isoform from IP3R3, eliciting $\mathrm{Ca}^{2+}$ concentration and signaling $[1,183]$. DMT is a hallucinogen found in human brain and is postulated to generate endogenously under cellular stress [184]. Mice injected with DMT showed hypermobility, but the effects were not observed in the Sig-1R KO phenotype [174], indicating DMT binding to Sig-1R to modulate its actions. Therefore, a model has been proposed that low concentration of DMT dissociates Sig-1Rs from BiP, allowing Sig-1Rs to regulate IP3R3s at the MAM. The $\mathrm{Ca}^{2+}$ signaling increased from the ER into mitochondria as well as the ATP production while higher concentrations of DMT induced the translocation of Sig-1Rs from the MAM to other cellular compartments, and inhibited ion channel's activities [185]. DMT producing enzyme also exhibited closed proximity to the Sig-1R in the motor neurons, implying the local synthesis of DMT in the wake of Sig-1R regulations [186]. Later studies showed that DMT mitigated hypoxic stress or modulated inflammatory responses via Sig- $1 \mathrm{R}$ in iPSC-derived cortical neurons or immune cells [184, 187]. Sig-1Rs associate with simple sphingolipids such as ceramides [76] which regulate mitochondrial functions such as eliciting the release of proapoptotic factors from the mitochondria, ROS production from mitochondria, and lipid synthesis, and are also implicated in CNS pathologies [188, 189]. Identifying the putative endogenous ligands excludes the Sig-1R as an orphan receptor, and the later discovery on the chaperoning function via the IP3R3 redefines the pivotal role of the Sig-1R, nevertheless, the subtle and coordinated actions/balances between Sig-1R and its putative endogenous ligands remain to be clarified to elucidate potential roles in the neurodegenerative diseases or other psychiatric illnesses toward Sig-1Rs.

\section{Conclusions and future perspective}

The function of Sig- $1 \mathrm{R}$ is activated when cells are under stress. The Sig-1R chaperone protein exerts pluripotent properties that can exist in the nuclear envelope, the nucleoplasmic reticulum, the MAM, the ER, and potentially the plasma membrane [190]. The main function of Sig- $1 \mathrm{R}$ is to regulate the $\mathrm{Ca}^{2+}$ gradient between ER and mitochondria through the MAM. Recently, the crystal structure of Sig-1R proposing a trimeric architecture with a single transmembrane domain in each protomer, with one side facing the ER lumen and the other side facing the surface of the ER in cells [191]. This discovery will accelerate the pace in understanding the ligand binding state and other important cellular mechanisms of Sig-1R. The Sig-1R has been proven to play certain roles in many neurodegenerative diseases. Ligands of the Sig-1R have also been shown to exhibit neuroprotective properties, providing some potential promising therapies in the future. It has been proposed that many aggregated proteins related to neurodegenerative disease were imported into mitochondria [192]. The regulatory functions of the Sig-1R chaperone on mitochondria thus deserve thorough investigations. The MAM, thus Sig-1Rs, represents an important target in the treatment of neurodegenerative diseases (Fig. 1). Whether Sig-1R interactions with other MAM tethering proteins may relate to those diseases remains to be fully investigated.

\footnotetext{
Abbreviations

3NP: 3-nitropropionic acid; AD: Alzheimer's disease; ALS: Amyotrophic lateral sclerosis; APOE: Apolipoprotein E; APP: Amyloid precursor protein; ARE: Antioxidant response element; $A \beta$ : $\beta$-amyloid; BAF: Barrier-toautointegration factor; CNS: Central nervous system; CYC1: Cytochrome C1; DMT: N,N-dimethyltryptamine; ER: Endoplasmic reticulum; FTLDMND: Frontotemporal lobar degeneration-motor neuron disease; GalCer: Galactosylceramide; GM1: Monosialotetrahexosylganglioside; $\mathrm{H}_{2} \mathrm{O}_{2}$ : Hydrogen peroxide; HD: Huntington's disease; HDAC: Histone deacetylase; Htt: Huntingtin; IP3: Inositol 1,4,5-trisphosphate; IP3R: Inositol 1,4,5-trisphosphate receptor; IP3R3: Type 3 inositol 1,4,5-trisphosphate receptor; IPAG: 1-(4-iodophenyl)-3-(2-adamantyl)guanidine; MAM: Mitochondrion-associated ER membrane; MAOB: Monoamine oxidase
} 
B; MPT: Mitochondrial permeability transition; mtDNA: mitochondrial DNA; NF-kB: Nuclear factor kB; NO: Nitric oxide; NQO1: NADPH quinone oxidoreductase 1; Nrf2: Nuclear factor erythroid 2-related factor 2; OL: Oligodendrocyte; PD: Parkinson's disease; PHB: Prohibitin; PLC: Phospholipase C; PP2A: Protein phosphatase 2A; Prdx6: Peroxiredoxin 6; PS1: Presenilin-1; PS2: Presenilin-2; PTPIP51: Protein tyrosine phosphatase interacting protein 51; ROS: Reactive oxidative species; Sig-1R: Sigma-1 receptor; SLC25A11: Solute carrier family 25 member 11; SLC25A39: Solute carrier family 25 member 39; Sp3: Pecific protein 3; StAR: Steroidogenic acute regulatory protein; TBI: Traumatic brain injury; UPR: Unfolded protein response; VAPB: Vesicle-associated membrane protein-associated protein B; VDAC: Voltage-dependent anion channel; VDAC1: Voltage-dependent anion channel 1; VDAC2: Voltage-dependent anion channel 2

\section{Acknowledgements}

We thank the Intramural Research Program of the National Institute on Drug Abuse of the National Institutes of Health, the United States Department of Health and Human Services, for the funding of this work.

\section{Funding}

This work was supported by the Intramural Research Program of the National Institute on Drug Abuse, National Institutes of Health, United States Department of Health and Human Services.

\section{Availability of data and materials}

All data in this review are already published and are available in public domains.

\section{Authors' contributions}

T-YW and S-YAT wrote the manuscript. T-PS edited and finalized the manuscript. All authors read and approved the final manuscript.

\section{Authors' information}

Tzu-Yu Weng (tyweng@gate.sinica.edu.tw), postdoc fellow, Academia Sinica Taiwan. Shang-Yi Anne Tsai (stsai@nih.gov), Scientific Review Officer, NIDA Division of Extramural Research, and Tsung-Ping Su (TSU@intra.nida.nih.gov), Chief, Cellular Pathobiology Section, Integrative Neuroscience Branch, Intramural Research Program, NIDA, NIH, Baltimore, Maryland.

\section{Ethics approval and consent to participate}

Not applicable.

\section{Consent for publication}

All authors have read the manuscript and agreed to the publication.

\section{Competing interests}

The authors declare that they have no competing interests.

\section{Publisher's Note}

Springer Nature remains neutral with regard to jurisdictional claims in published maps and institutional affiliations.

\section{Author details}

${ }^{1}$ Cellular Pathobiology Section, Integrative Neuroscience Branch, Intramural Research Program, National Institute on Drug Abuse, NIH, DHHS, IRP, NIDA $\mathrm{NIH}$, Triad Bldg. suite 3512, 333 Cassell Drive, Baltimore, MD 21224, USA. ${ }^{2}$ Genomics Research Center, Academia Sinica, Taipei, Taiwan.

Received: 31 May 2017 Accepted: 5 September 2017

Published online: 16 September 2017

\section{References}

1. Hayashi T, Su TP. Regulating ankyrin dynamics: Roles of sigma-1 receptors. Proc Natl Acad Sci U S A. 2001:98:491-6.

2. Hayashi T, Su TP. Sigma-1 receptor chaperones at the ER-mitochondrion interface regulate $\mathrm{Ca}(2+)$ signaling and cell survival. Cell. 2007;131:596-610.

3. Srivats S, Balasuriya D, Pasche M, Vistal G, Edwardson JM, Taylor CW, et al. Sigma 1 receptors inhibit store-operated $\mathrm{Ca} 2+$ entry by attenuating coupling of STIM1 to Orai1. J Cell Biol. 2016;213:65-79.

4. Crottes D, Guizouarn H, Martin P, Borgese F, Soriani O. The sigma-1 receptor: a regulator of cancer cell electrical plasticity? Front Physiol. 2013;4:175.
5. Mavlyutov TA, Guo LW, Epstein ML, Ruoho AE. Role of the Sigma-1 receptor in Amyotrophic Lateral Sclerosis (ALS). J Pharmacol Sci. 2015; 127:10-6.

6. Hayashi T, Su TP. Sigma-1 receptors at galactosylceramide-enriched lipid microdomains regulate oligodendrocyte differentiation. Proc Natl Acad Sci U S A. 2004;101:14949-54.

7. Tsai SY, Pokrass MJ, Klauer NR, Nohara H, Su TP. Sigma-1 receptor regulates Tau phosphorylation and axon extension by shaping p35 turnover via myristic acid. Proc Natl Acad Sci U S A. 2015;112:6742-7.

8. Ciesielski J, Su TP, Tsai SY. Myristic acid hitchhiking on sigma-1 receptor to fend off neurodegeneration. Receptors Clin Investig. 2016;3

9. Tsai SY, Hayashi T, Harvey BK, Wang Y, Wu WW, Shen RF, et al. Sigma-1 receptors regulate hippocampal dendritic spine formation via a free radicalsensitive mechanism involving Rac1xGTP pathway. Proc Natl Acad Sci U S A. 2009:106:22468-73.

10. Tsai SY, Pokrass MJ, Klauer NR, De Credico NE, Su TP. Sigma-1 receptor chaperones in neurodegenerative and psychiatric disorders. Expert Opin Ther Targets. 2014;18:1461-76.

11. Mori T, Hayashi T, Hayashi E, Su TP. Sigma-1 receptor chaperone at the ERmitochondrion interface mediates the mitochondrion-ER-nucleus signaling for cellular survival. PLoS One. 2013;8:e76941.

12. Tsai SY, Chuang JY, Tsai MS, Wang XF, Xi ZX, Hung JJ, et al. Sigma-1 receptor mediates cocaine-induced transcriptional regulation by recruiting chromatin-remodeling factors at the nuclear envelope. Proc Natl Acad Sci U S A. 2015;112:E6562-70.

13. Newmeyer DD, Ferguson-Miller S. Mitochondria: releasing power for life and unleashing the machineries of death. Cell. 2003;112:481-90.

14. Taanman JW. The mitochondrial genome: structure, transcription, translation and replication. Biochim Biophys Acta. 1999;1410:103-23.

15. Wang Z, Wu M. An integrated phylogenomic approach toward pinpointing the origin of mitochondria. Sci Rep. 2015;5:7949.

16. Kuhlbrandt W. Structure and function of mitochondrial membrane protein complexes. BMC Biol. 2015;13:89.

17. Mishra P, Chan DC. Metabolic regulation of mitochondrial dynamics. J Cell Biol. 2016;212:379-87.

18. Youle RJ van der Bliek AM. Mitochondrial fission, fusion, and stress. Science. 2012;337:1062-5.

19. Carelli V, Chan DC. Mitochondrial DNA: impacting central and peripheral nervous systems. Neuron. 2014;84:1126-42.

20. Duchen MR. Mitochondria and calcium: from cell signalling to cell death. J Physiol. 2000;529(Pt 1):57-68

21. Murphy MP. How mitochondria produce reactive oxygen species. Biochem J. 2009:417:1-13.

22. Wang C, Youle RJ. The role of mitochondria in apoptosis*. Annu Rev Genet. 2009:43:95-118

23. Federico A, Cardaioli E, Da Pozzo P, Formichi P, Gallus GN, Radi E. Mitochondria, oxidative stress and neurodegeneration. J Neurol Sci. 2012; 322:254-62.

24. Chinnery PF. Mitochondrial Disorders Overview. In Pagon RA, Adam MP, Ardinger $\mathrm{HH}$, et al., editors. GeneReviews(R). Seattle (WA): University of Washington, Seattle; 1993.

25. Copeland DE, Dalton AJ. An association between mitochondria and the endoplasmic reticulum in cells of the pseudobranch gland of a teleost. Biophys Biochem Cytol. 1959;5:393-6.

26. Rusinol $A E$, Cui Z, Chen MH, Vance JE. A unique mitochondria-associated membrane fraction from rat liver has a high capacity for lipid synthesis and contains pre-Golgi secretory proteins including nascent lipoproteins. J Biol Chem. 1994;269:27494-502.

27. Stone SJ, Vance JE. Phosphatidylserine synthase-1 and -2 are localized to mitochondria-associated membranes. J Biol Chem. 2000;275:34534-40

28. Fujimoto M, Hayashi T. New insights into the role of mitochondriaassociated endoplasmic reticulum membrane. Int Rev Cell Mol Biol. 2011; 292:73-117.

29. Vance JE. MAM (mitochondria-associated membranes) in mammalian cells: lipids and beyond. Biochim Biophys Acta. 1841;2014:595-609.

30. Rizzuto R, Brini M, Murgia M, Pozzan T. Microdomains with high Ca2+ close to IP3-sensitive channels that are sensed by neighboring mitochondria. Science. 1993;262:744-7.

31. Rizzuto $R$, Duchen MR, Pozzan T. Flirting in little space: the ER/mitochondria Ca2+ liaison. Sci STKE. 2004;2004:re1. 
32. Mendes CC, Gomes DA, Thompson M, Souto NC, Goes TS, Goes AM, et al. The type III inositol 1,4,5-trisphosphate receptor preferentially transmits apoptotic Ca2+ signals into mitochondria. J Biol Chem. 2005;280:40892-900.

33. Vance JE. Phospholipid synthesis in a membrane fraction associated with mitochondria. J Biol Chem. 1990;265:7248-56.

34. Csordas G, Varnai P, Golenar T, Roy S, Purkins G, Schneider TG, et al. Imaging interorganelle contacts and local calcium dynamics at the ER-mitochondrial interface. Mol Cell. 2010;39:121-32.

35. Decuypere JP, Monaco G, Bultynck G, Missiaen L, De Smedt H, Parys JB. The $\mathrm{IP}(3)$ receptor-mitochondria connection in apoptosis and autophagy. Biochim Biophys Acta. 1813;2011:1003-13.

36. Shioda N, Ishikawa K, Tagashira H, Ishizuka T, Yawo H, Fukunaga K. Expression of a truncated form of the endoplasmic reticulum chaperone protein, sigma1 receptor, promotes mitochondrial energy depletion and apoptosis. J Biol Chem. 2012;287:23318-31.

37. Tagashira H, Shinoda Y, Shioda N, Fukunaga K. Methyl pyruvate rescues mitochondrial damage caused by SIGMAR1 mutation related to amyotrophic lateral sclerosis. Biochim Biophys Acta. 1840;2014:3320-34.

38. Natsvlishvili N, Goguadze N, Zhuravliova E, Mikeladze D. Sigma-1 receptor directly interacts with Rac1-GTPase in the brain mitochondria. BMC Biochem. 2015;16:11

39. Tagashira H, Zhang C, Lu YM, Hasegawa H, Kanai H, Han F, et al. Stimulation of sigma1-receptor restores abnormal mitochondrial $\mathrm{Ca}(2)(+)$ mobilization and ATP production following cardiac hypertrophy. Biochim Biophys Acta. 1830;2013:3082-94.

40. Cory S, Huang DC, Adams JM. The BCl-2 family: roles in cell survival and oncogenesis. Oncogene. 2003;22:8590-607.

41. Meunier J, Hayashi T. Sigma-1 receptors regulate Bcl-2 expression by reactive oxygen species-dependent transcriptional regulation of nuclear factor kappaB. J Pharmacol Exp Ther. 2010;332:388-97.

42. Yang S, Bhardwaj A, Cheng J, Alkayed NJ, Hurn PD, Kirsch JR. Sigma receptor agonists provide neuroprotection in vitro by preserving bcl-2. Anesth Analg. 2007;104:1179-84. tables of contents

43. Ha Y, Shanmugam AK, Markand S, Zorrilla E, Ganapathy V, Smith SB. Sigma receptor 1 modulates ER stress and Bcl2 in murine retina. Cell Tissue Res. 2014;356:15-27.

44. Tchedre KT, Yorio T. sigma-1 receptors protect RGC-5 cells from apoptosis by regulating intracellular calcium, Bax levels, and caspase-3 activation. Invest Ophthalmol Vis Sci. 2008;49:2577-88.

45. Spruce BA, Campbell LA, McTavish N, Cooper MA, Appleyard MV, O'Neill M, et al. Small molecule antagonists of the sigma-1 receptor cause selective release of the death program in tumor and self-reliant cells and inhibit tumor growth in vitro and in vivo. Cancer Res. 2004;64:4875-86.

46. Achison M, Boylan MT, Hupp TR, Spruce BA. HIF-1alpha contributes to tumour-selective killing by the sigma receptor antagonist rimcazole. Oncogene. 2007;26:1137-46.

47. Shen K, Zhang Y, Lv X, Chen X, Zhou R, Nguyen LK, et al. Molecular Mechanisms Involving Sigma-1 Receptor in Cell Apoptosis of BV-2 Microglial Cells Induced by Methamphetamine. CNS Neurol Disord Drug Targets. 2016; 15:857-65.

48. Liu CY, Kaufman RJ. The unfolded protein response. J Cell Sci. 2003;1 16:1861-2.

49. Bravo R, Vicencio JM, Parra V, Troncoso R, Munoz JP, Bui M, et al. Increased ER-mitochondrial coupling promotes mitochondrial respiration and bioenergetics during early phases of ER stress. J Cell Sci. 2011;124:2143-52.

50. Bravo R, Gutierrez T, Paredes F, Gatica D, Rodriguez AE, Pedrozo Z, et al. Endoplasmic reticulum: ER stress regulates mitochondrial bioenergetics. Int J Biochem Cell Biol. 2012;44:16-20.

51. Tsai SY, Rothman RK, Su TP. Insights into the Sigma-1 receptor chaperone's cellular functions: a microarray report. Synapse. 2012;66:42-51.

52. Ha Y, Dun Y, Thangaraju M, Duplantier J, Dong Z, Liu K, et al. Sigma receptor 1 modulates endoplasmic reticulum stress in retinal neurons. Invest Ophthalmol Vis Sci. 2011;52:527-40.

53. Mitsuda T, Omi T, Tanimukai H, Sakagami Y, Tagami S, Okochi M, et al. Sigma1Rs are upregulated via PERK/elF2alpha/ATF4 pathway and execute protective function in ER stress. Biochem Biophys Res Commun. 2011;415:519-25.

54. Omi T, Tanimukai H, Kanayama D, Sakagami $Y$, Tagami $S$, Okochi $M$, et al. Fluvoxamine alleviates ER stress via induction of Sigma-1 receptor. Cell Death Dis. 2014;5:e1332.

55. Uttara B, Singh AV, Zamboni P, Mahajan RT. Oxidative stress and neurodegenerative diseases: a review of upstream and downstream antioxidant therapeutic options. Curr Neuropharmacol. 2009;7:65-74.
56. Meunier J, leni J, Maurice T. The anti-amnesic and neuroprotective effects of donepezil against amyloid beta25-35 peptide-induced toxicity in mice involve an interaction with the sigma1 receptor. Br J Pharmacol. 2006;149: 998-1012.

57. Dong H, Ma Y, Ren Z, Xu B, Zhang Y, Chen J, et al. Sigma-1 Receptor Modulates Neuroinflammation After Traumatic Brain Injury. Cell Mol Neurobiol. 2016;36:639-45.

58. Wang L, Eldred JA, Sidaway P, Sanderson J, Smith AJ, Bowater RP, et al. Sigma 1 receptor stimulation protects against oxidative damage through suppression of the ER stress responses in the human lens. Mech Ageing Dev. 2012;133:665-74.

59. Pal A, Fontanilla D, Gopalakrishnan A, Chae YK, Markley UL, Ruoho AE. The sigma-1 receptor protects against cellular oxidative stress and activates antioxidant response elements. Eur J Pharmacol. 2012;682:12-20.

60. Johnson JA, Johnson DA, Kraft AD, Calkins MJ, Jakel RJ, Vargas MR, et al. The Nrf2-ARE pathway: an indicator and modulator of oxidative stress in neurodegeneration. Ann N Y Acad Sci. 2008;1147:61-9.

61. Wang J, Shanmugam A, Markand S, Zorrilla E, Ganapathy V, Smith SB. Sigma 1 receptor regulates the oxidative stress response in primary retinal Muller glial cells via NRF2 signaling and system xc(-), the $\mathrm{Na}(+)$-independent glutamate-cystine exchanger. Free Radic Biol Med. 2015;86:25-36.

62. Dinkova-Kostova AT, Abramov AY. The emerging role of Nrf2 in mitochondrial function. Free Radic Biol Med. 2015;88:179-88.

63. Strom J, Xu B, Tian X, Chen QM. Nrf2 protects mitochondrial decay by oxidative stress. FASEB J. 2016;30:66-80.

64. Su TC, Lin SH, Lee PT, Yeh SH, Hsieh TH, Chou SY, et al. The sigma-1 receptor-zinc finger protein 179 pathway protects against hydrogen peroxide-induced cell injury. Neuropharmacology. 2016;105:1-9.

65. He C, Klionsky DJ. Regulation mechanisms and signaling pathways of autophagy. Annu Rev Genet. 2009;43:67-93.

66. Lee J, Giordano S, Zhang J. Autophagy, mitochondria and oxidative stress: cross-talk and redox signalling. Biochem J. 2012;441:523-40.

67. Cardenas C, Miller RA, Smith I, Bui T, Molgo J, Muller M, et al. Essential regulation of cell bioenergetics by constitutive InsP3 receptor $\mathrm{Ca} 2+$ transfer to mitochondria. Cell. 2010;142:270-83.

68. Geisler S, Holmstrom KM, Skujat D, Fiesel FC, Rothfuss OC, Kahle PJ, et al. PINK1/Parkin-mediated mitophagy is dependent on VDAC1 and p62/ SQSTM1. Nat Cell Biol. 2010;12:119-31.

69. Hamasaki M, Furuta N, Matsuda A, Nezu A, Yamamoto A, Fujita N, et al. Autophagosomes form at ER-mitochondria contact sites. Nature. 2013;495: 389-93.

70. Schrock JM, Spino CM, Longen CG, Stabler SM, Marino JC, Pasternak GW, et al. Sequential cytoprotective responses to Sigma1 ligand-induced endoplasmic reticulum stress. Mol Pharmacol. 2013;84:751-62.

71. Vollrath JT, Sechi A, Dreser A, Katona I, Wiemuth D, Vervoorts J, et al. Loss of function of the ALS protein SigR1 leads to ER pathology associated with defective autophagy and lipid raft disturbances. Cell Death Dis. 2014;5: e1290.

72. Miki Y, Mori F, Kon T, Tanji K, Toyoshima Y, Yoshida M, et al. Accumulation of the sigma-1 receptor is common to neuronal nuclear inclusions in various neurodegenerative diseases. Neuropathology. 2014; 34:148-58.

73. Cao L, Walker MP, Vaidya NK, Fu M, Kumar S, Kumar A. Cocaine-Mediated Autophagy in Astrocytes Involves Sigma 1 Receptor, PI3K, mTOR, Atg5/7, Beclin-1 and Induces Type II Programed Cell Death. Mol Neurobiol. 2016;53: 4417-30.

74. Kasahara R, Yamamoto N, Suzuki K, Sobue K. The sigma1 receptor regulates accumulation of GM1 ganglioside-enriched autophagosomes in astrocytes. Neuroscience. 2017:340:176-87.

75. MacVicar TD, Mannack LV, Lees RM, Lane JD. Targeted siRNA Screens Identify ER-to-Mitochondrial Calcium Exchange in Autophagy and Mitophagy Responses in RPE1 Cells. Int J Mol Sci. 2015;16:13356-80.

76. Hayashi T, Fujimoto M. Detergent-resistant microdomains determine the localization of sigma-1 receptors to the endoplasmic reticulummitochondria junction. Mol Pharmacol. 2010;77:517-28.

77. Marriott KS, Prasad M, Thapliyal V, Bose HS. Sigma-1 receptor at the mitochondrial-associated endoplasmic reticulum membrane is responsible for mitochondrial metabolic regulation. J Pharmacol Exp Ther. 2012;343: 578-86.

78. Maurya SR, Mahalakshmi R. VDAC-2: Mitochondrial outer membrane regulator masquerading as a channel? FEBS J. 2016;283:1831-6. 
79. Naghdi S, Hajnoczky G. VDAC2-specific cellular functions and the underlying structure. Biochim Biophys Acta. 1863;2016:2503-14.

80. Prasad M, Kaur J, Pawlak KJ, Bose M, Whittal RM, Bose HS. Mitochondriaassociated endoplasmic reticulum membrane (MAM) regulates steroidogenic activity via steroidogenic acute regulatory protein (StAR)voltage-dependent anion channel 2 (VDAC2) interaction. J Biol Chem. 2015; 290:2604-16.

81. Schmitt T, Ogris C, Sonnhammer EL. FunCoup 3.0: database of genomewide functional coupling networks. Nucleic Acids Res. 2014;42:D380-8.

82. Su TP, Su TC, Nakamura Y, Tsai SY. The Sigma-1 Receptor as a Pluripotent Modulator in Living Systems. Trends Pharmacol Sci. 2016;37:262-78.

83. Sun J, Trumpower BL. Superoxide anion generation by the cytochrome bc1 complex. Arch Biochem Biophys. 2003;419:198-206.

84. Yu Z, Poppe JL, Wang X. Mitochondrial mechanisms of neuroglobin's neuroprotection. Oxidative Med Cell Longev. 2013;2013:756989.

85. Merkwirth C, Langer T. Prohibitin function within mitochondria: essential roles for cell proliferation and cristae morphogenesis. Biochim Biophys Acta. 2009;1793:27-32.

86. Palmieri F. The mitochondrial transporter family (SLC25): physiological and pathological implications. Pflugers Arch. 2004;447:689-709.

87. Wilkins HM, Kirchhof D, Manning E, Joseph JW, Linseman DA. Mitochondrial glutathione transport is a key determinant of neuronal susceptibility to oxidative and nitrosative stress. J Biol Chem. 2013;288:5091-101.

88. Kann O, Kovacs R. Mitochondria and neuronal activity. Am J Physiol Cell Physiol. 2007;292:C641-57

89. Lin MT, Beal MF. Mitochondrial dysfunction and oxidative stress in neurodegenerative diseases. Nature. 2006;443:787-95.

90. Johri A, Beal MF. Mitochondrial dysfunction in neurodegenerative diseases. J Pharmacol Exp Ther. 2012;342:619-30.

91. Paillusson S, Stoica R, Gomez-Suaga P, Lau DH, Mueller S, Miller T, et al. There's Something Wrong with my MAM; the ER-Mitochondria Axis and Neurodegenerative Diseases. Trends Neurosci. 2016;39:146-57.

92. van Vliet AR, Verfaillie T, Agostinis P. New functions of mitochondria associated membranes in cellular signaling. Biochim Biophys Acta. 1843; 2014:2253-62

93. Rodriguez-Arribas M, Yakhine-Diop SM, Pedro JM, Gomez-Suaga P, GomezSanchez R, Martinez-Chacon G, et al. Mitochondria-Associated Membranes (MAMs): Overview and Its Role in Parkinson's Disease. Mol Neurobiol. 2016; 54:6287-6303

94. Nguyen L, Lucke-Wold BP, Mookerjee SA, Cavendish JZ, Robson MJ, Scandinaro AL, et al. Role of sigma-1 receptors in neurodegenerative diseases. J Pharmacol Sci. 2015;127:17-29.

95. Nguyen L, Lucke-Wold BP, Mookerjee S, Kaushal N, Matsumoto RR. Sigma-1 Receptors and Neurodegenerative Diseases: Towards a Hypothesis of Sigma-1 Receptors as Amplifiers of Neurodegeneration and Neuroprotection. Adv Exp Med Biol. 2017;964:133-52.

96. Jin JL, Fang M, Zhao YX, Liu XY. Roles of sigma-1 receptors in Alzheimer's disease. Int J Clin Exp Med. 2015;8:4808-20.

97. Mishina M, Ishiwata K, Ishii K, Kitamura S, Kimura Y, Kawamura K, et al. Function of sigma1 receptors in Parkinson's disease. Acta Neurol Scand. 2005;112:103-7.

98. Hyrskyluoto A, Pulli I, Tornqvist K, Ho TH, Korhonen L, Lindholm D. Sigma-1 receptor agonist PRE084 is protective against mutant huntingtin-induced cell degeneration: involvement of calpastatin and the NF-kappaB pathway. Cell Death Dis. 2013;4:e646.

99. Ruscher K, Wieloch $\mathrm{T}$. The involvement of the sigma-1 receptor in neurodegeneration and neurorestoration. J Pharmacol Sci. 2015;127:30-5.

100. Katnik C, Guerrero WR, Pennypacker KR, Herrera Y, Cuevas J. Sigma-1 receptor activation prevents intracellular calcium dysregulation in cortical neurons during in vitro ischemia. J Pharmacol Exp Ther. 2006; 319:1355-65.

101. Romero L, Zamanillo D, Nadal X, Sanchez-Arroyos R, Rivera-Arconada I, Dordal A, et al. Pharmacological properties of S1RA, a new sigma-1 receptor antagonist that inhibits neuropathic pain and activity-induced spinal sensitization. Br J Pharmacol. 2012;166:2289-306.

102. Hayashi T, Su TP. Sigma-1 receptor ligands: potential in the treatment of neuropsychiatric disorders. CNS Drugs. 2004;18:269-84.

103. Sha S, Hong J, Qu WJ, Lu ZH, Li L, Yu WF, et al. Sex-related neurogenesis decrease in hippocampal dentate gyrus with depressivelike behaviors in sigma-1 receptor knockout mice. Eur Neuropsychopharmacol. 2015;25:1275-86.
104. Langa F, Codony X, Tovar V, Lavado A, Gimenez E, Cozar P, et al. Generation and phenotypic analysis of sigma receptor type I (sigma 1) knockout mice. Eur J Neurosci. 2003;18:2188-96.

105. Sabino V, Cottone P, Parylak SL, Steardo L, Zorrilla EP. Sigma-1 receptor knockout mice display a depressive-like phenotype. Behav Brain Res. 2009; 198:472-6.

106. Devi L, Prabhu BM, Galati DF, Avadhani NG, Anandatheerthavarada HK. Accumulation of amyloid precursor protein in the mitochondrial import channels of human Alzheimer's disease brain is associated with mitochondrial dysfunction. J Neurosci. 2006;26:9057-68.

107. Caspersen C, Wang N, Yao J, Sosunov A, Chen X, Lustbader JW, et al. Mitochondrial Abeta: a potential focal point for neuronal metabolic dysfunction in Alzheimer's disease. FASEB J. 2005;19:2040-1.

108. Manczak M, Anekonda TS, Henson E, Park BS, Quinn J, Reddy PH. Mitochondria are a direct site of A beta accumulation in Alzheimer's disease neurons: implications for free radical generation and oxidative damage in disease progression. Hum Mol Genet. 2006;15:1437-49.

109. Yan SD, Stern DM. Mitochondrial dysfunction and Alzheimer's disease: role of amyloid-beta peptide alcohol dehydrogenase (ABAD). Int J Exp Pathol. 2005;86:161-71.

110. Zhao XL, Wang WA, Tan JX, Huang JK, Zhang X, Zhang BZ, et al. Expression of beta-amyloid induced age-dependent presynaptic and axonal changes in Drosophila. J Neurosci. 2010;30:1512-22.

111. Schreiner B, Hedskog L, Wiehager B, Ankarcrona M. Amyloid-beta peptides are generated in mitochondria-associated endoplasmic reticulum membranes. J Alzheimers Dis. 2015;43:369-74.

112. Behensky AA, Yasny IE, Shuster AM, Seredenin SB, Petrov AV, Cuevas J. Afobazole activation of sigma-1 receptors modulates neuronal responses to amyloid-beta25-35. J Pharmacol Exp Ther. 2013;347:468-77.

113. Hedskog L, Pinho CM, Filadi R, Ronnback A, Hertwig L, Wiehager B, et al. Modulation of the endoplasmic reticulum-mitochondria interface in Alzheimer's disease and related models. Proc Natl Acad Sci U S A. 2013;110: 7916-21.

114. Toyohara J, Sakata M, Ishiwata K. Imaging of sigma1 receptors in the human brain using PET and [11C]SA4503. Cent Nerv Syst Agents Med Chem. 2009; 9:190-6.

115. Barbero-Camps E, Fernandez A, Baulies A, Martinez L, Fernandez-Checa JC, Colell A. Endoplasmic reticulum stress mediates amyloid beta neurotoxicity via mitochondrial cholesterol trafficking. Am J Pathol. 2014;184:2066-81.

116. Giorgi C, Ito K, Lin HK, Santangelo C, Wieckowski MR, Lebiedzinska M, et al. PML regulates apoptosis at endoplasmic reticulum by modulating calcium release. Science. 2010;330:1247-51.

117. Placido Al, Pereira CM, Correira SC, Carvalho C, Oliveira CR, Moreira PI. Phosphatase 2A Inhibition Affects Endoplasmic Reticulum and Mitochondria Homeostasis Via Cytoskeletal Alterations in Brain Endothelial Cells. Mol Neurobiol. 2017:54:154-68.

118. Huang Y, Zheng L, Halliday G, Dobson-Stone C, Wang Y, Tang HD, et al. Genetic polymorphisms in sigma-1 receptor and apolipoprotein E interact to influence the severity of Alzheimer's disease. Curr Alzheimer Res. 2011;8: 765-70.

119. Tambini MD, Pera M, Kanter E, Yang H, Guardia-Laguarta C, Holtzman D, et al. ApoE4 upregulates the activity of mitochondria-associated ER membranes. EMBO Rep. 2016;17:27-36.

120. Area-Gomez E, de Groof AJ, Boldogh I, Bird TD, Gibson GE, Koehler CM, et al. Presenilins are enriched in endoplasmic reticulum membranes associated with mitochondria. Am J Pathol. 2009;175:1810-6.

121. Area-Gomez E, Del Carmen Lara Castillo M, Tambini MD, Guardia-Laguarta C, de Groof AJ, Madra M, et al. Upregulated function of mitochondriaassociated ER membranes in Alzheimer disease. EMBO J. 2012;31:4106-23.

122. Zampese E, Fasolato C, Kipanyula MJ, Bortolozzi M, Pozzan T, Pizzo P. Presenilin 2 modulates endoplasmic reticulum (ER)-mitochondria interactions and $\mathrm{Ca} 2+$ cross-talk. Proc Natl Acad Sci U S A. 2011;108:2777-82.

123. Sepulveda-Falla D, Barrera-Ocampo A, Hagel C, Korwitz A, Vinueza-Veloz MF, Zhou K, et al. Familial Alzheimer's disease-associated presenilin-1 alters cerebellar activity and calcium homeostasis. J Clin Invest. 2014;124:1552-67.

124. Manczak M, Reddy PH. Abnormal interaction between the mitochondrial fission protein Drp1 and hyperphosphorylated tau in Alzheimer's disease neurons: implications for mitochondrial dysfunction and neuronal damage. Hum Mol Genet. 2012;21:2538-47.

125. Quintanilla RA, Matthews-Roberson TA, Dolan PJ, Johnson GV. Caspasecleaved tau expression induces mitochondrial dysfunction in immortalized 
cortical neurons: implications for the pathogenesis of Alzheimer disease. J Biol Chem. 2009;284:18754-66.

126. Dauer W, Przedborski S. Parkinson's disease: mechanisms and models. Neuron. 2003;39:889-909.

127. Devi L, Raghavendran V, Prabhu BM, Avadhani NG, Anandatheerthavarada HK. Mitochondrial import and accumulation of alpha-synuclein impair complex I in human dopaminergic neuronal cultures and Parkinson disease brain. J Biol Chem. 2008;283:9089-100.

128. Parihar MS, Parihar A, Fujita M, Hashimoto M, Ghafourifar P. Mitochondrial association of alpha-synuclein causes oxidative stress. Cell Mol Life Sci. 2008; 65:1272-84.

129. Deng H, Dodson MW, Huang H, Guo M. The Parkinson's disease genes pink1 and parkin promote mitochondrial fission and/or inhibit fusion in Drosophila. Proc Natl Acad Sci U S A. 2008;105:14503-8.

130. Clark IE, Dodson MW, Jiang C, Cao JH, Huh JR, Seol JH, et al. Drosophila pink1 is required for mitochondrial function and interacts genetically with parkin. Nature. 2006;441:1162-6.

131. Park J, Lee SB, Lee S, Kim Y, Song S, Kim S, et al. Mitochondrial dysfunction in Drosophila PINK1 mutants is complemented by parkin. Nature. 2006;441: 1157-61.

132. Zhang L, Shimoji M, Thomas B, Moore DJ, Yu SW, Marupudi NI, et al. Mitochondrial localization of the Parkinson's disease related protein DJ-1: implications for pathogenesis. Hum Mol Genet. 2005;14:2063-73.

133. Hayashi T, Ishimori C, Takahashi-Niki K, Taira T, Kim YC, Maita H, et al. DJ-1 binds to mitochondrial complex I and maintains its activity. Biochem Biophys Res Commun. 2009;390:667-72.

134. Junn E, Jang WH, Zhao X, Jeong BS, Mouradian MM. Mitochondrial localization of DJ-1 leads to enhanced neuroprotection. J Neurosci Res. 2009;87:123-9

135. Wang X, Yan MH, Fujioka H, Liu J, Wilson-Delfosse A, Chen SG, et al. LRRK2 regulates mitochondrial dynamics and function through direct interaction with DLP1. Hum Mol Genet. 2012;21:1931-44.

136. Mori T, Hayashi T, Su TP. Compromising sigma-1 receptors at the endoplasmic reticulum render cytotoxicity to physiologically relevant concentrations of dopamine in a nuclear factor-kappaB/BCl-2-dependent mechanism: potential relevance to Parkinson's disease. J Pharmacol Exp Ther. 2012;341:663-71.

137. Cali T, Ottolini D, Negro A, Brini M. alpha-Synuclein controls mitochondrial calcium homeostasis by enhancing endoplasmic reticulum-mitochondria interactions. J Biol Chem. 2012;287:17914-29.

138. Guardia-Laguarta C, Area-Gomez E, Rub C, Liu Y, Magrane J, Becker D, et al. alpha-Synuclein is localized to mitochondria-associated ER membranes. J Neurosci. 2014;34:249-59.

139. Paillusson S, Gomez-Suaga P, Stoica R, Little D, Gissen P, Devine MJ, et al. alpha-Synuclein binds to the ER-mitochondria tethering protein VAPB to disrupt $\mathrm{Ca} 2+$ homeostasis and mitochondrial ATP production. Acta Neuropathol. 2017;134:129-49.

140. Hao LY, Giasson BI, Bonini NM. DJ-1 is critical for mitochondrial function and rescues PINK1 loss of function. Proc Natl Acad Sci U S A. 2010;107:9747-52.

141. Cali T, Ottolini D, Negro A, Brini M. Enhanced parkin levels favor ERmitochondria crosstalk and guarantee $\mathrm{Ca}(2+)$ transfer to sustain cell bioenergetics. Biochim Biophys Acta. 1832;2013:495-508.

142. Ottolini D, Cali T, Negro A, Brini M. The Parkinson disease-related protein DJ1 counteracts mitochondrial impairment induced by the tumour suppressor protein p53 by enhancing endoplasmic reticulum-mitochondria tethering. Hum Mol Genet. 2013;22:2152-68.

143. Roos RA. Huntington's disease: a clinical review. Orphanet J Rare Dis. 2010;5:40.

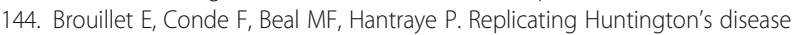
phenotype in experimental animals. Prog Neurobiol. 1999;59:427-68.

145. Choo YS, Johnson GV, MacDonald M, Detloff PJ, Lesort M. Mutant huntingtin directly increases susceptibility of mitochondria to the calciuminduced permeability transition and cytochrome c release. Hum Mol Genet. 2004;13:1407-20.

146. Wang H, Lim PJ, Karbowski M, Monteiro MJ. Effects of overexpression of huntingtin proteins on mitochondrial integrity. Hum Mol Genet. 2009;18: 737-52.

147. Shirendeb UP, Calkins MJ, Manczak M, Anekonda V, Dufour B, McBride JL, et al. Mutant huntingtin's interaction with mitochondrial protein Drp1 impairs mitochondrial biogenesis and causes defective axonal transport and synaptic degeneration in Huntington's disease. Hum Mol Genet. 2012;21: 406-20.
148. Reijonen S, Putkonen N, Norremolle A, Lindholm D, Korhonen L. Inhibition of endoplasmic reticulum stress counteracts neuronal cell death and protein aggregation caused by N-terminal mutant huntingtin proteins. Exp Cell Res. 2008:314:950-60.

149. Miki Y, Tanji K, Mori F, Wakabayashi K. Sigma-1 receptor is involved in degradation of intranuclear inclusions in a cellular model of Huntington's disease. Neurobiol Dis. 2015;74:25-31.

150. Higo T, Hamada K, Hisatsune C, Nukina N, Hashikawa T, Hattori M, et al. Mechanism of ER stress-induced brain damage by IP(3) receptor. Neuron. 2010;68:865-78.

151. Squitieri F, Di Pardo A, Favellato M, Amico E, Maglione V, Frati L. Pridopidine, a dopamine stabilizer, improves motor performance and shows neuroprotective effects in Huntington disease R6/2 mouse model. J Cell Mol Med. 2015;19:2540-8.

152. Geva M, Kusko R, Soares H, Fowler KD, Birnberg T, Barash S, et al. Pridopidine activates neuroprotective pathways impaired in Huntington Disease. Hum Mol Genet. 2016;25:3975-87.

153. Ryskamp D, Wu J, Geva M, Kusko R, Grossman I, Hayden M, et al. The sigma1 receptor mediates the beneficial effects of pridopidine in a mouse model of Huntington disease. Neurobiol Dis. 2017;97:46-59.

154. Kiernan MC, Vucic S, Cheah BC, Turner MR, Eisen A, Hardiman O, et al. Amyotrophic lateral sclerosis. Lancet. 2011;377:942-55.

155. Borthwick GM, Johnson MA, Ince PG, Shaw PJ, Turnbull DM. Mitochondrial enzyme activity in amyotrophic lateral sclerosis: implications for the role of mitochondria in neuronal cell death. Ann Neurol. 1999;46:787-90.

156. Siklos L, Engelhardt J, Harati Y, Smith RG, Joo F, Appel SH. Ultrastructural evidence for altered calcium in motor nerve terminals in amyotropic lateral sclerosis. Ann Neurol. 1996;39:203-16.

157. Kong J, Xu Z. Massive mitochondrial degeneration in motor neurons triggers the onset of amyotrophic lateral sclerosis in mice expressing a mutant SOD1. J Neurosci. 1998;18:3241-50.

158. Vande Velde C, Miller TM, Cashman NR, Cleveland DW. Selective association of misfolded ALS-linked mutant SOD1 with the cytoplasmic face of mitochondria. Proc Natl Acad Sci U S A. 2008:105:4022-7.

159. Magrane J, Sahawneh MA, Przedborski S, Estevez AG, Manfredi G. Mitochondrial dynamics and bioenergetic dysfunction is associated with synaptic alterations in mutant SOD1 motor neurons. J Neurosci. 2012;32: 229-42.

160. Deng J, Yang M, Chen Y, Chen X, Liu J, Sun S, et al. FUS Interacts with HSP60 to Promote Mitochondrial Damage. PLoS Genet. 2015;11:e1005357.

161. Wang W, Wang L, Lu J, Siedlak SL, Fujioka H, Liang J, et al. The inhibition of TDP-43 mitochondrial localization blocks its neuronal toxicity. Nat Med. 2016;22:869-78

162. Wong YC, Holzbaur EL. Temporal dynamics of PARK2/parkin and OPTN/ optineurin recruitment during the mitophagy of damaged mitochondria. Autophagy. 2015;11:422-4.

163. Lopez-Gonzalez R, Lu Y, Gendron TF, Karydas A, Tran H, Yang D, et al. Poly(GR) in C9ORF72-Related ALS/FTD Compromises Mitochondrial Function and Increases Oxidative Stress and DNA Damage in iPSC-Derived Motor Neurons. Neuron. 2016;92:383-91.

164. Prause J, Goswami A, Katona I, Roos A, Schnizler M, Bushuven E, et al. Altered localization, abnormal modification and loss of function of Sigma receptor-1 in amyotrophic lateral sclerosis. Hum Mol Genet. 2013;22:1581600.

165. Bernard-Marissal N, Medard JJ, Azzedine H, Chrast R. Dysfunction in endoplasmic reticulum-mitochondria crosstalk underlies SIGMAR1 loss of function mediated motor neuron degeneration. Brain. 2015;138:875-90.

166. Watanabe $\mathrm{S}$, llieva $\mathrm{H}$, Tamada $\mathrm{H}$, Nomura $\mathrm{H}$, Komine O, Endo F, et al. Mitochondria-associated membrane collapse is a common pathomechanism in SIGMAR1- and SOD1-linked ALS. EMBO Mol Med. 2016; 8:1421-37.

167. Neumann M, Sampathu DM, Kwong LK, Truax AC, Micsenyi MC, Chou TT, et al. Ubiquitinated TDP-43 in frontotemporal lobar degeneration and amyotrophic lateral sclerosis. Science. 2006;314:130-3.

168. Stoica R, De Vos K, Paillusson S, Mueller S, Sancho RM, Lau KF, et al. ERmitochondria associations are regulated by the VAPB-PTPIP51 interaction and are disrupted by ALS/FTD-associated TDP-43. Nat Commun. 2014;5: 3996.

169. Luty AA, Kwok JB, Dobson-Stone C, Loy CT, Coupland KG, Karlstrom H, et al. Sigma nonopioid intracellular receptor 1 mutations cause frontotemporal lobar degeneration-motor neuron disease. Ann Neurol. 2010;68:639-49. 
170. Al-Saif A, Al-Mohanna F, Bohlega S. A mutation in sigma-1 receptor causes juvenile amyotrophic lateral sclerosis. Ann Neurol. 2011;70:913-9.

171. Fukunaga $K$, Shinoda $Y$, Tagashira $H$. The role of SIGMAR1 gene mutation and mitochondrial dysfunction in amyotrophic lateral sclerosis. J Pharmacol Sci. 2015;127:36-41.

172. Su TP, London ED, Jaffe JH. Steroid binding at sigma receptors suggests a link between endocrine, nervous, and immune systems. Science. 1988;240: 219-21.

173. Maurice $T$, Junien $J$, Privat A. Dehydroepiandrosterone sulfate attenuates dizocilpine-induced learning impairment in mice via sigma 1-receptors. Behav Brain Res. 1997;83:159-64.

174. Fontanilla D, Johannessen M, Hajipour AR, Cozzi NV, Jackson MB, Ruoho AE. The hallucinogen $\mathrm{N}, \mathrm{N}$-dimethyltryptamine (DMT) is an endogenous sigma-1 receptor regulator. Science. 2009;323:934-7.

175. Ruoho AE, Chu UB, Ramachandran S, Fontanilla D, Mavlyutov T, Hajipour AR. The ligand binding region of the sigma-1 receptor: studies utilizing photoaffinity probes, sphingosine and N-alkylamines. Curr Pharm Des. 2012. 18:920-9.

176. Ramachandran S, Chu UB, Mavlyutov TA, Pal A, Pyne S, Ruoho AE. The sigma1 receptor interacts with $\mathrm{N}$-alkyl amines and endogenous sphingolipids. Eur J Pharmacol. 2009:609:19-26.

177. Hayashi T. Sigma-1 receptor: the novel intracellular target of neuropsychotherapeutic drugs. J Pharmacol Sci. 2015;127:2-5.

178. Irwin RW, Yao J, Hamilton RT, Cadenas E, Brinton RD, Nilsen J. Progesterone and estrogen regulate oxidative metabolism in brain mitochondria. Endocrinology. 2008;149:3167-75.

179. De Nicola AF, Gonzalez Deniselle MC, Garay L, Meyer M, GargiuloMonachelli G, Guennoun R, et al. Progesterone protective effects in neurodegeneration and neuroinflammation. J Neuroendocrinol. 2013;25: 1095-103.

180. Gonzalez Deniselle MC, Lopez Costa JJ, Gonzalez SL, Labombarda F, Garay L, Guennoun $\mathrm{R}$, et al. Basis of progesterone protection in spinal cord neurodegeneration. J Steroid Biochem Mol Biol. 2002;83:199-209.

181. Carroll JC, Rosario ER, Chang L, Stanczyk FZ, Oddo S, LaFerla FM, et al. Progesterone and estrogen regulate Alzheimer-like neuropathology in female 3xTg-AD mice. J Neurosci. 2007;27:13357-65.

182. Kauffman FC, Sharp S, Allan BB, Burchell A, Coughtrie MW. Microsomal steroid sulfatase: interactions with cytosolic steroid sulfotransferases. Chem Biol Interact. 1998;109:169-82.

183. Su TP, Hayashi T, Maurice T, Buch S, Ruoho AE. The sigma-1 receptor chaperone as an inter-organelle signaling modulator. Trends Pharmacol Sci. 2010;31:557-66.

184. Szabo A, Kovacs A, Riba J, Djurovic S, Rajnavolgyi E, Frecska E. The Endogenous Hallucinogen and Trace Amine N,N-Dimethyltryptamine (DMT) Displays Potent Protective Effects against Hypoxia via Sigma-1 Receptor Activation in Human Primary iPSC-Derived Cortical Neurons and MicrogliaLike Immune Cells. Front Neurosci. 2016;10:423.

185. Su TP, Hayashi T, Vaupel DB. When the endogenous hallucinogenic trace amine N,N-dimethyltryptamine meets the sigma-1 receptor. Sci Signal. 2009; 2:pe12.

186. Mavlyutov TA, Epstein ML, Liu P, Verbny Yl, Ziskind-Conhaim L, Ruoho AE. Development of the sigma-1 receptor in C-terminals of motoneurons and colocalization with the $\mathrm{N}, \mathrm{N}^{\prime}$-dimethyltryptamine forming enzyme, indole-Nmethyl transferase. Neuroscience. 2012;206:60-8.

187. Szabo A, Kovacs A, Frecska E, Rajnavolgyi E. Psychedelic N,Ndimethyltryptamine and 5-methoxy-N,N-dimethyltryptamine modulate innate and adaptive inflammatory responses through the sigma-1 receptor of human monocyte-derived dendritic cells. PLoS One. 2014;9:e106533.

188. Siskind LJ. Mitochondrial ceramide and the induction of apoptosis. J Bioenerg Biomembr. 2005;37:143-53.

189. Jana A, Hogan EL, Pahan K. Ceramide and neurodegeneration: susceptibility of neurons and oligodendrocytes to cell damage and death. J Neurol Sci. 2009;278:5-15

190. Mavlyutov TA, Yang H, Epstein ML, Ruoho AE, Yang J, Guo LW. APEX2enhanced electron microscopy distinguishes sigma-1 receptor localization in the nucleoplasmic reticulum. Oncotarget. 2017;8:51317-51330.

191. Schmidt HR, Zheng S, Gurpinar E, Koehl A, Manglik A, Kruse AC. Crystal structure of the human sigma1 receptor. Nature. 2016:532:527-30.

192. Ruan L, Zhou C, Jin E, Kucharavy A, Zhang Y, Wen Z, et al. Cytosolic proteostasis through importing of misfolded proteins into mitochondria. Nature. 2017;543:443-6.

\section{Submit your next manuscript to BioMed Central and we will help you at every step:}

- We accept pre-submission inquiries

- Our selector tool helps you to find the most relevant journal

- We provide round the clock customer support

- Convenient online submission

- Thorough peer review

- Inclusion in PubMed and all major indexing services

- Maximum visibility for your research

Submit your manuscript at www.biomedcentral.com/submit 